Article

\title{
Somatic Embryogenesis and Plant Regeneration from Cotyledon and Hypocotyl Explants of Fagopyrum esculentum Moench lpls Mutant
}

\author{
Yue Fei ${ }^{1,+}$, Lan-Xiang Wang ${ }^{1,+}$, Zheng-Wu Fang ${ }^{2}$ and Zhi-Xiong Liu 1,2,* \\ 1 College of Horticulture and Gardening, Yangtze University, Jingzhou 434025, Hubei, China; \\ 201771409@yangtzeu.edu.cn (Y.F.); 201672386@yangtzeu.edu.cn (L.-X.W.) \\ 2 Institute of Crop Genetics and Breeding, Yangtze University, Jingzhou 434025, Hubei, China; \\ fangzhengwu88@yangtzeu.edu.cn \\ * Correspondence: zxliu@yangtzeu.edu.cn; Tel.: +86-716-8066260 \\ $\dagger$ Authors contributed equally to the manuscript.
}

Received: 14 October 2019; Accepted: 14 November 2019; Published: 18 November 2019

\begin{abstract}
Buckwheat (Fagopyrum esculentum, Family Polygonaceae) is an annual pseudo-cereal crop with healing benefits. However, the genetic improvement of common buckwheat has achieved only limited success, mainly due to buckwheat's dimorphic flowers and heteromorphic self-incompatibility. Here, we develop a useful protocol for indirect somatic embryogenesis and subsequent plant regeneration from hypocotyl explants of F. esculentum. Firstly, the initial calli of hypocotyl explants were induced on Murashige and Skoog (MS) basal medium containing $2.0 \mathrm{mgL}^{-1} 2,4-\mathrm{D}$ and $1.5 \mathrm{mgL}^{-1}$ 6-BA for 30 days culture, and then the yellowish white friable embryogenic calli were developed when the initial calli were transferred to fresh MS basal medium supplemented with $1.0 \mathrm{mgL}^{-1} 6-\mathrm{BA}$ and $0.5 \mathrm{mgL}^{-1}$ thidiazuron (TDZ)two to three times subculture at 40-60 days intervals. Subsequently, the somatic embryos were able to germinate from embryogenic callus sub-cultured on MS basal medium containing $1.0 \mathrm{mgL}^{-1} 6$-BA and $0.5 \mathrm{mgL}^{-1} \mathrm{TDZ}$ with $15 \%$ potato puree for 20 days subculture. Finally, maximum mean percentage $(75.75 \%)$ of somatic embryo-derived plants were obtained when the mature somatic embryos were transferred to MS basal medium without growth regulators for 40 days culture. Our result provides a useful protocol for plant regeneration and SE from hypocotyl explants of F. esculentum.
\end{abstract}

Keywords: callus induction; Fagopyrum esculentum; hypocotyl explants; plant regeneration; somatic embryogenesis

\section{Introduction}

Buckwheat (Fagopyrum esculentum, Family Polygonaceae) is an annual pseudo-cereal crop originated from southern China [1]. Buckwheat seeds (strictly achenes) contain proteins with healing benefits rich in lysine, dietary fiber, antioxidants, phenolic compounds and rutin [1-3]. Moreover, Buckwheat has a short growing period, tolerance of cool climate and high altitudes, resistance to most cereal diseases and can be adapted to almost all types of soil, which make it an important crop cultivated for centuries in Asia, Europe and North America for forage, human consumption and medicine [2,4-7]. However, the genetic improvement of common buckwheat has achieved only limited success, mainly due to buckwheat's heteromorphic self-incompatibility [4]. Buckwheat possesses dimorphic flowers, with populations being equally composed of plants with pin flowers (long pistil and short stamen) (Figure 1A) and plants with thrum flowers (short pistil and long stamen) (Figure 1B), and legitimate cross pollinations occur strictly between anthers and stigmas of equivalent height in 
different floral morphs [8,9]. Furthermore, the entomophilous flowers are open and fertile for only one day [9]. All these factors accounting for the low seed set and grain yields have made Buckwheat fall out of favor as crops for culture despite its nutritious and healing benefits.

Improving the efficiency of hybrid-breeding programs and yield, requires new germplasm resources available for free cross-pollination with both type flowers of Buckwheat. We have developed a self-compatible Buckwheat line from a natural mutant individual of buckwheat variety 'Bei-zao-sheng' in Jingzhou, Hubei Province, China. In addition, the mutant individual has flowers with long pistil and long stamen, and legitimate cross-pollinations occur freely with pin, thrum and lpls (long pistil and long stamen, lpls) flowers. Hence, it was designated as Buckwheat lpls mutant (Figure 1C). Moreover, we have developed a lpls line that only produce flower with long pistil and long stamen through segregated pollination. However, the mechanisms underlying floral morph changes associated with self-compatibility in F. esculentum lpls mutant remain unclear. Somatic embryogenesis (SE) is one of the best examples of the remarkable developmental plasticity of plants, in which committed somatic cells can dedifferentiate and acquire the ability to form an embryo and regenerate an entire plant [10]. SE is not only one of ideal approaches for large scale production of true to type plants and long-term ex situ conservation of useful germplasms, but also provides a very useful tool for basic research studies in cell biology and genetic engineering [11-13].

Previous studies showed that indirect somatic embryogenesis from immature embryos of buckwheat occurred on $\mathrm{B}_{5}$ medium plus $2.2 \mathrm{mgL}^{-1}$ 6-Benzylaminopurine (BAP) $0.17 \mathrm{mgL}^{-1}$ Indole-3-acetic acid (IAA) and $6 \%$ sucrose after pretreatment on $\mathrm{B}_{5}$ medium plus $5.0 \mathrm{mgL}^{-1} 2,4-\mathrm{D}$, $0.1 \mathrm{mgL}^{-1}$ Kinetin (KT) and $6 \%$ sucrose for 5 days [14]. Moreover, somatic embryogenesis from hypocotyl explants of buckwheat were reported on MS medium containing $2.0 \mathrm{mgL}^{-1}$ IAA, $1.0 \mathrm{mgL}^{-1}$ $\mathrm{KT}, 1.0 \mathrm{mgL}^{-1}$ 6-BA and 3\% sucrose, and 2,4-D did not show any significant effect on callus induction or embryogenesis [15]. However, recent study suggested that a combination of $0.5 \mathrm{mgL}^{-1} 2,4-\mathrm{D}$ and $0.2 \mathrm{mgL}^{-1} \mathrm{BAP}$ with sucrose showed obvious induction of somatic embryogenesis from cotyledon and hypocotyl explants of buckwheat [16]. Here, we developed a useful protocol for plant regeneration and SE from hypocotyl explants of F. esculentum, which provides a potential method for producing self-compatibility lines of buckwheat.
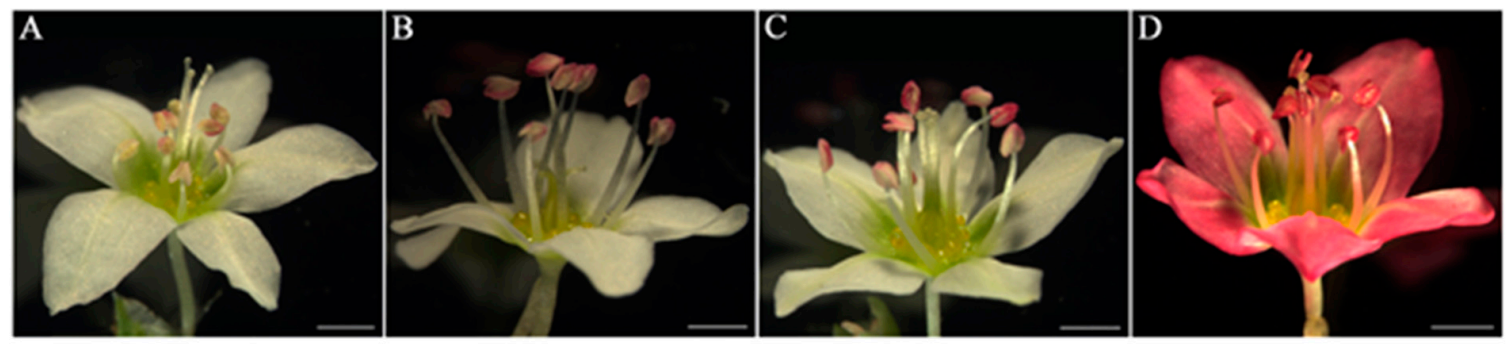

Figure 1. Heterodistylous flowers of F. esculentum. (A) Pin flower with long pistil and short stamens; (B) thrum flower with short pistil and long stamens. (C) lpls flower with long pistil and long stamen;

(D) the lpls flower found in hybrid daughter lines between lpls mutant and red flower buckwheat variety 'Xi-nong 9976'. Scale bar $=1 \mathrm{~mm}$.

\section{Materials and Methods}

\subsection{Plant Material and Callus Induction}

The achenes of Buckwheat (F. esculentum) lpls mutant were washed in running water for $30 \mathrm{~min}$, followed by shaking in $75 \%$ ethanol for $1 \mathrm{~min}$, and then immersed in $0.1 \% \mathrm{HgCl}_{2}$ for $15 \mathrm{~min}$. After rinsing 4-5 times in sterile water, the achenes were dehulled and the seeds were squeezed out. The seeds (dehulled achenes) were immersed in $0.1 \% \mathrm{HgCl}_{2}$ for $2 \mathrm{~min}$, and then rinsed $4-5$ times in sterile water. The sterilized seeds were sown on the surface of hormone-free MS basal medium [17], which contained $3 \%$ sucrose and was gelled with $0.7 \%$ agar, and germinated under $14 \mathrm{~h}$ photoperiod at 
$25 \pm 2{ }^{\circ} \mathrm{C}$. Cotyledon and hypocotyl explants of $12-15$ days old seedlings were excised. The hypocotyl explants were excised in approximately $1 \mathrm{~cm}$ length segments, and the cotyledon explants were cut into $1 \mathrm{~cm}$ long segments attached with approximately $0.5 \mathrm{~cm}$ long cotyledon petiole. The explants were randomly plated, six per culture bottle, onto hormone-free MS basal medium and MS basal medium supplemented with different concentrations $\left(0.5,1.0,2.0\right.$ or $\left.4.0 \mathrm{mgL}^{-1}\right)$ of 2,4-D in combination with various levels $\left(0.5,1.0\right.$ or $\left.1.5 \mathrm{mgL}^{-1}\right)$ of 6-BA or KT for a preliminary screening of culture media for callus induction. Three culture bottles were used for each treatment and every treatment was repeated three times. Percentage response for callus formation was recorded after culture for 30 days. Means and standard errors for the frequencies of explants that produced callus were calculated.

\subsection{Callus Maintenance and Embryogenic Callus Induction}

The callus clumps obtained above were separately excised and then transferred, six per culture bottle, to hormone-free MS basal medium and MS basal medium plus various concentrations $(1.0,2.0$ or $\left.3.0 \mathrm{mgL}^{-1}\right)$ of 6-BA in combination with different levels $\left(0.5,1.0\right.$ or $\left.1.5 \mathrm{mgL}^{-1}\right)$ of KT or TDZ for screening of subculture media. Three culture bottles were used for each treatment and three replications were performed for each treatment. The red-green compact callus clumps obtained were transferred to a fresh medium at $35-40$ days intervals. After subculture media tested for screening of the best subculture media, the red-green compact callus clumps obtained were transferred, six per culture bottle, to MS basal medium containing $1.0 \mathrm{mgL}^{-1}$, or $2.0 \mathrm{mgL}^{-1}$ 6-BA in combination with different levels $\left(0.5,1.0\right.$ or $\left.1.5 \mathrm{mgL}^{-1}\right)$ of $\mathrm{KT}$ or TDZ for callus proliferation and embryogenic callus induction.

\subsection{Embryogenic Callus Maintenance, Somatic Embryos Germination and Plant Regeneration}

The yellowish white friable embryogenic callus clumps induced on MS basal medium supplemented with $1.0 \mathrm{mgL}^{-1} 6-\mathrm{BA}$ and $0.5 \mathrm{mgL}^{-1} \mathrm{TDZ}$ were transferred to MS basal medium plus $1.0 \mathrm{mgL}^{-1}$ 6-BA and $0.5 \mathrm{mgL}^{-1} \mathrm{TDZ}$ in combination with different concentrations $\left(0.5,1.0\right.$ or $\left.1.5 \mathrm{mgL}^{-1}\right)$ of $\alpha$-Naphthalene acetic acid (NAA), or IAA for screening of subculture media for proliferation of embryogenic callus and germination of somatic embryos. Previous study suggested that potato juice or banana juice could improve growth of plantlets of different Dendrobium species [18]. In addition, Jiang suggested that potato homogenate was appropriate for protocorm-like body propagation of Oncidium and thought that potato homogenate contains many nutrients that are benefic for the growth of plants [19]. Hence, the yellowish white friable embryogenic callus clumps obtained were also transferred to MS basal medium containing $1.0 \mathrm{mgL}^{-1}$ 6-BA and $0.5 \mathrm{mgL}^{-1} \mathrm{TDZ}$ in combination with different levels $(5 \%, 10 \%$ or $15 \%)$ of mashed bananas or potato puree for screening of subculture media for proliferation of embryogenic callus and germination of somatic embryos. In addition, the yellowish white friable embryogenic callus clumps obtained were also transferred to MS basal medium containing $1.0 \mathrm{mgL}^{-1} 6-\mathrm{BA}, 0.5 \mathrm{mgL}^{-1} \mathrm{TDZ}$ and $15 \%(v / v)$ potato puree in combination with different levels $\left(0.5,1.0,1.5 \mathrm{mgL}^{-1}\right)$ of ABA for screening of subculture media for proliferation of embryogenic callus and germination of somatic embryos. After subculture for 20 days, the proliferation times of embryogenic callus and the mean numbers of germinating somatic embryos were calculated, respectively. Furthermore, the germinating somatic embryos obtained above were transferred to hormone-free MS basal medium, MS basal medium plus $1.0 \mathrm{mgL}^{-1} 6-\mathrm{BA}$ and $0.5 \mathrm{mgL}^{-1} \mathrm{KT}$, MS basal medium plus $1.0 \mathrm{mgL}^{-1}$ 6-BA in combination with various concentrations $\left(0.5,1.0\right.$ or $\left.1.5 \mathrm{mgL}^{-1}\right)$ of IAA, or NAA, MS basal medium supplemented with $0.5 \mathrm{mgL}^{-1}$ active carbon, MS basal medium plus $0.5 \mathrm{mgL}^{-1}$ active carbon and $1.0 \mathrm{mgL}^{-1}$ 6-BA in combination with $0.5 \mathrm{mgL}^{-1} \mathrm{IAA}$, or $0.5 \mathrm{mgL}^{-1}$ NAA for screening of culture media for plant regeneration, respectively. After culture for 40 days, the percentage of somatic embryo-derived plant was calculated. Cultures were maintained at $25 \pm 2{ }^{\circ} \mathrm{C}$ and under $14 \mathrm{~h}$ photoperiod. 


\subsection{Histological Analysis}

The samples for histological observations were collected and fixed in FAA (38\% formaldehyde: acetic acid: $70 \%$ ethanol = 1:1:18, by volume). Samples were dehydrated in a graded ethanol series, cleared in a xylene series, infiltrated with molten paraffin, and then embedded into a paraffin block according to Liu et al. [20]. The embedded samples were serially sectioned at a thickness of $8 \mu \mathrm{m}$ with a Leica RM2235 rotary microtome. The sections were subsequently stained with Periodic Acid-Schiff and Naphthol Yellow S, and then observed under an OLYMPUS BX63 microscope, fitted with a camera.

\subsection{Observations and Statistical Analyses}

The Callus induction frequency (\%) [(number of explants with callus/total number of explants) $\times$ 100] was calculated after culture for 30 days. The proliferation times of embryogenic callus [(weights of embryogenic callus after proliferation/preliminary weights of embryogenic callus)] and mean numbers of germinating somatic embryos were calculated after subculture for 20 days. The percentage of somatic embryo-derived plant [(number of somatic embryo-derived plant/number of somatic embryos cultured $\times 100$ ] was calculated after culture for 40 days. All experiments were carried out with three biological replicates, and data were expressed as mean \pm standard errors. Statistical significance was determined using one-way ANOVA with Duncan's Multiple Range Test at $p<0.05$ level. Among the treatments, the average figures followed by different letters were presented at significant differences.

\section{Results}

\subsection{Callus Induction}

The cotyledon and hypocotyl explants became swollen at cut margins after 5 days of inoculation, and subsequently produced the initial callus during the next 25 days of culture. After 30 days of culture on hormone-free MS basal medium and MS basal medium plus various concentrations (0.5, 1.0, 2.0, or $\left.4.0 \mathrm{mgL}^{-1}\right)$ of 2,4-D in combination with different levels $\left(0.5,1.0\right.$, or $\left.1.5 \mathrm{mgL}^{-1}\right)$ of 6-BA or KT, the initial calli were developed at cotyledon edges and hypocotyl basal end, and the frequency of cotyledon and hypocotyl explants with calli produced was evaluated (Supplementary Table S1). Among the media tested, the best for callus induction of cotyledon explants was MS basal medium containing $1.0 \mathrm{mgL}^{-1}$ 2,4-D and $1.5 \mathrm{mgL}^{-1} 6-\mathrm{BA}$, since $100 \%$ of cultured explants produced callus accompanied by a small amount of embryogenic callus on this medium (Figure 2A,B). Moreover, most of calli produced by cotyledon explants are compact and yellow-red. However, a large number of hairy roots were induced in the cotyledon explants on MS basal medium plus $0.5 \mathrm{mgL}^{-1} 2,4-\mathrm{D}$ in combination with different levels $\left(0.5,1.0\right.$ or $\left.1.5 \mathrm{mgL}^{-1}\right)$ of KT (Figure 2C). Among the media tested, the best for callus induction of hypocotyl explants was MS basal medium containing $2.0 \mathrm{mgL}^{-1}$ 2,4-D and $1.5 \mathrm{mgL}^{-1}$ 6-BA, since $100 \%$ of cultured explants produced callus accompanied by a small amount of embryogenic callus on this medium (Figure 2D). In addition, most of calli produced by hypocotyl explants are compact and wine red. Of the cultured hypocotyl explants, $100 \%$ were observed to produce wine red callus on $1.0 \mathrm{mgL}^{-1}$ 2,4-D in combination with $1.0 \mathrm{mgL}^{-1}$, or $1.5 \mathrm{mgL}^{-1}$ 6-BA (Figure 2E). However, a small amount of calli and hairy roots were induced in the hypocotyl explants on MS basal medium plus $0.5 \mathrm{mgL}^{-1}$, (or $1.0 \mathrm{mgL}^{-1}$ ) 2,4-D in combination with different levels $\left(0.5,1.0\right.$ or $1.5 \mathrm{mgL}^{-1}$ ) of KT (Figure 2F).

\subsection{Callus Maintenance and Embryogenic Callus Induction}

After two to three subcultures on MS basal medium plus $1.0 \mathrm{mgL}^{-1}$, or $2.0 \mathrm{mgL}^{-1}$ 6-BA in combination with different levels $\left(0.5,1.0\right.$, or $\left.1.5 \mathrm{mgL}^{-1}\right)$ of KT or TDZ, the color of compact callus gradually turned red-green. A lot of adventitious shoots appeared from red-green compact callus on MS basal medium containing $1.0 \mathrm{mgL}^{-1} 6-\mathrm{BA}$ and $1.5 \mathrm{mgL}^{-1} \mathrm{KT}$ (Figure 3A), while red-green compact callus proliferated fast and maintain the initial texture and color when sub-cultured on MS basal medium supplemented with $2.0 \mathrm{mgL}^{-1}$ 6-BA and $0.5 \mathrm{mgL}^{-1} \mathrm{TDZ}$ (Figures 3B and 4A,E). However, the green compact callus proliferated slowly, gradually turned from green to pale green and 
subsequently germinated white crystalline structures from the callus surface when sub-cultured on MS basal medium supplemented with $1.0 \mathrm{mgL}^{-1}$ 6-BA and $0.5 \mathrm{mgL}^{-1} \mathrm{TDZ}$ (Figure 4B,F), while the red compact callus proliferated fast and maintain the initial texture and color when sub-cultured on this medium (Figure 3C). Moreover, after 60 days of sub-cultured on MS basal medium supplemented with $1.0 \mathrm{mgL}^{-1} 6-\mathrm{BA}$ and $0.5 \mathrm{mgL}^{-1} \mathrm{TDZ}$, the green compact callus was gradually converted to yellowish white friable embryogenic callus (Figures 3D and $4 C, G$ ). However, part of the yellowish white friable embryogenic callus gradually turned into friable non-embryonic callus after subcultures on MS basal medium containing $1.0 \mathrm{mgL}^{-1} 6$-BA and $0.5 \mathrm{mgL}^{-1} \mathrm{TDZ}$ for many times (Figure $4 \mathrm{D}, \mathrm{H}$ ). In addition, we also found that the compact callus from hypocotyl explants was more suitable for callus proliferation and embryogenic callus induction than that from the cotyledon explants.

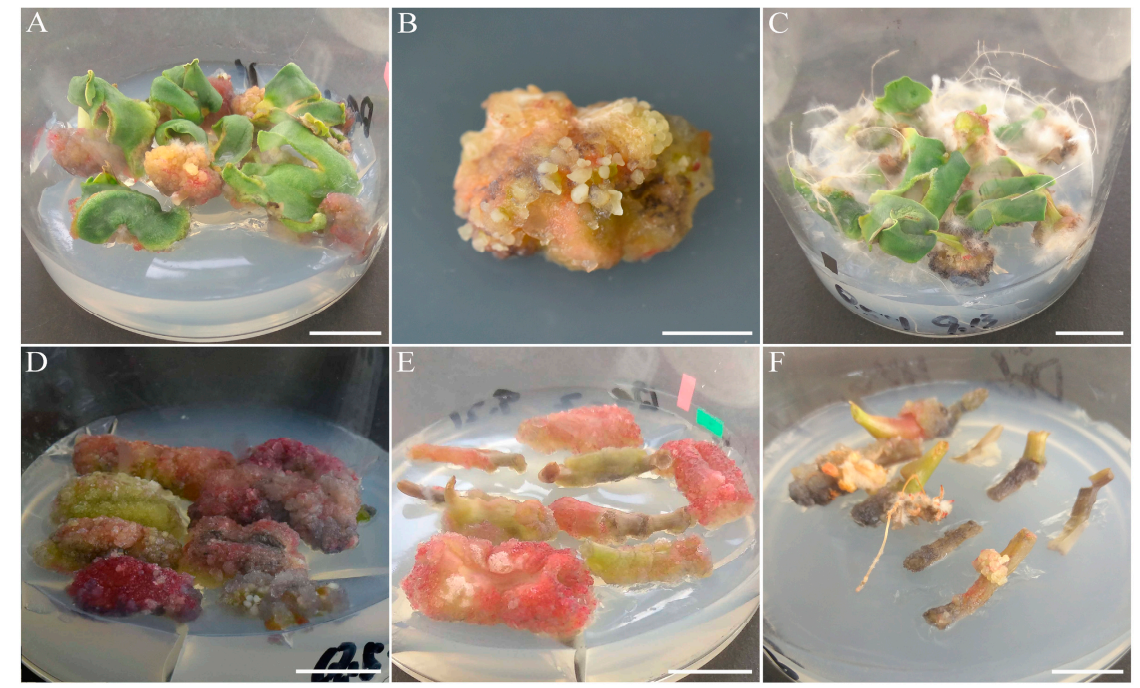

Figure 2. Callus induction from cotyledon (A-C) and hypocotyl (D-F) explants of Fagopyrum esculentum. (A) Red compact callus formation from cotyledon explants on MS basal medium containing $1.0 \mathrm{mgL}^{-1}$ 2,4-D and $1.5 \mathrm{mgL}^{-1}$ 6-BA; (B) callus accompanied by a small amount of embryogenic callus on MS basal medium containing $1.0 \mathrm{mgL}^{-1} 2,4$-D and $1.5 \mathrm{mgL}^{-1}$ 6-BA. (C) hairy roots formation from cotyledon explants on MS basal medium plus $0.5 \mathrm{mgL}^{-1}$ 2,4-D and $1.0 \mathrm{mgL}^{-1} \mathrm{KT}$; (D) wine-red compact callus formation from hypocotyl explants on MS basal medium containing $2.0 \mathrm{mgL}^{-1} 2,4-\mathrm{D}$ and $1.5 \mathrm{mgL}^{-1}$ 6-BA; (E) callus formation from hypocotyl explants on MS basal medium containing $1.0 \mathrm{mgL}^{-1} 2,4-\mathrm{D}$ and $1.5 \mathrm{mgL}^{-1} 6-\mathrm{BA} ;(\mathrm{F})$ a small amount of calli and hairy roots formation from hypocotyl explants on MS basal medium plus $0.5 \mathrm{mgL}^{-1}$ 2,4-D and $1.5 \mathrm{mgL}^{-1} \mathrm{KT}$. Scale bar: (A, C, D-F) $1 \mathrm{~cm}$; (B) $0.5 \mathrm{~cm}$.
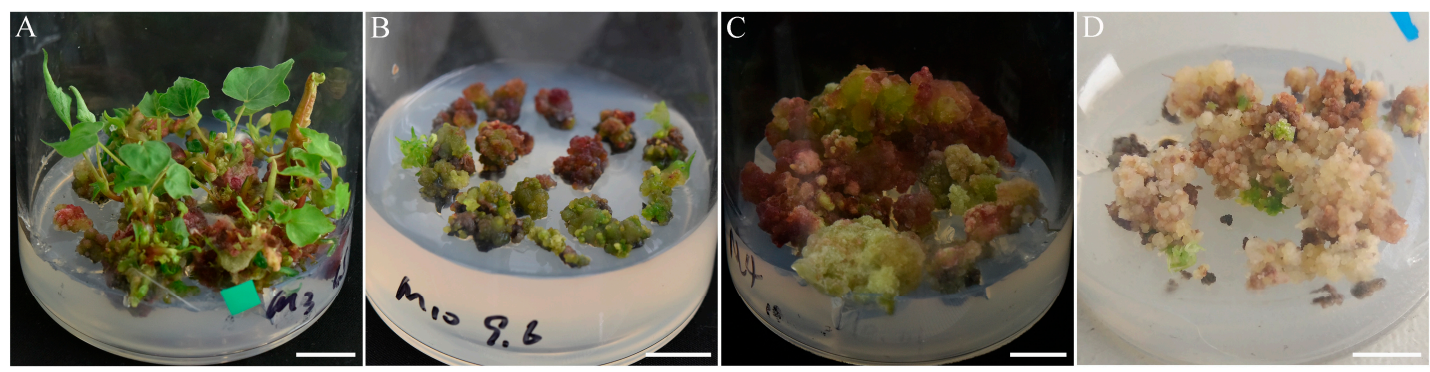

Figure 3. Subculture of callus and embryogenic callus induction from the hypocotyl explants of Fagopyrum esculentum. (A) Adventitious shoots appeared from red-green compact callus on MS basal medium containing $1.0 \mathrm{mgL}^{-1}$ 6-BA and $1.5 \mathrm{mgL}^{-1} \mathrm{KT}$; (B) red-green compact callus proliferated on MS basal medium supplemented with $2.0 \mathrm{mgL}^{-1}$ 6-BA and $0.5 \mathrm{mgL}^{-1} \mathrm{TDZ}$; (C) yellowish white friable embryogenic callus and the red-green compact callus proliferated on MS basal medium supplemented with $1.0 \mathrm{mgL}^{-1}$ 6-BA and $0.5 \mathrm{mgL}^{-1} \mathrm{TDZ}$; (D) yellowish white friable embryogenic callus induction from green compact callus on MS basal medium supplemented with $1.0 \mathrm{mgL}^{-1}$ 6-BA and $0.5 \mathrm{mgL}^{-1}$ TDZ. Scale bar: (A-D) $1 \mathrm{~cm}$. 

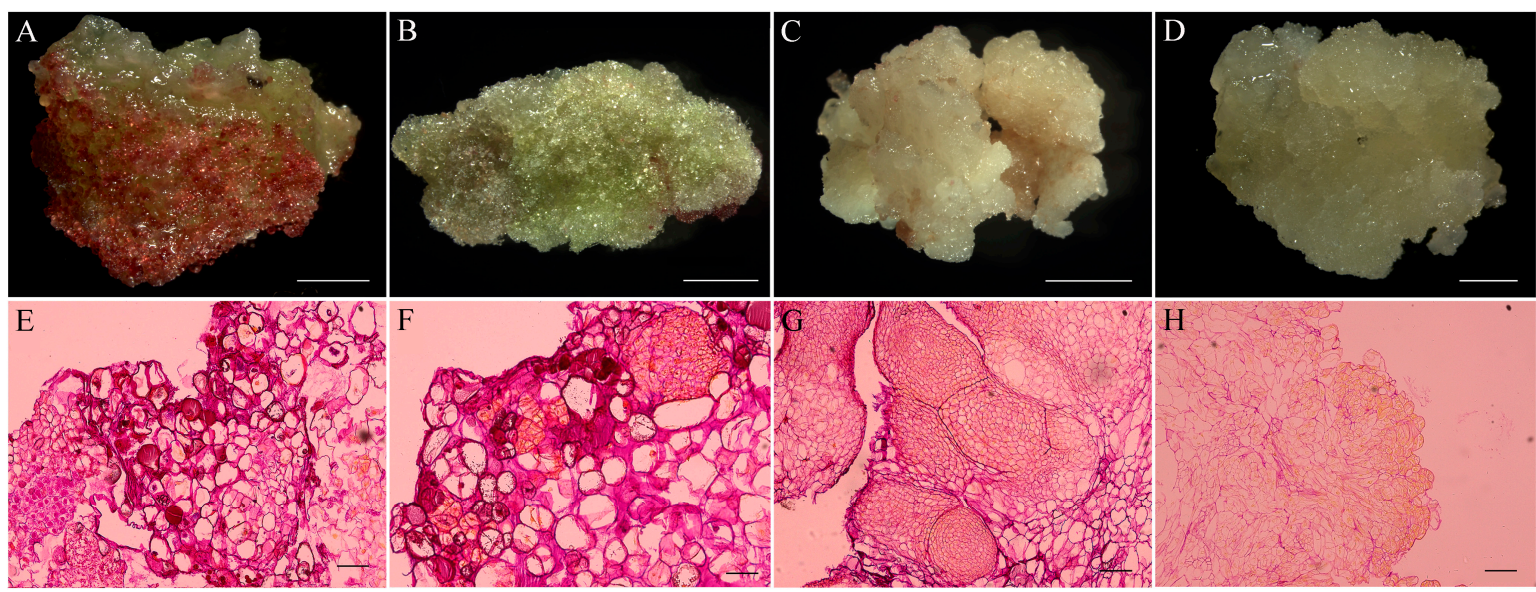

$\mathrm{H}$

Figure 4. Histological analysis of callus and embryogenic callus originated from hypocotyl explants of Fagopyrum esculentum. (A) Red-green compact callus; (B) pale green callus covered white crystalline structures; (C) yellowish white friable embryogenic callus; (D) friable non-embryonic callus; (E) histological section of red-green compact callus; (F) histological section of pale green callus covered with white crystalline structures; $(\mathbf{G})$ histological section of yellowish white friable embryogenic callus; (H) histological section of soft and friable non-embryonic callus. Scale bar: (A-D) $2 \mathrm{~cm}$; (E-H) $500 \mu \mathrm{m}$.

\subsection{Embryogenic Callus Maintenance, Somatic Embryos Germination and Plant Regeneration}

Among the media tested (Supplementary Tables S2-S4), the best for proliferation of embryogenic callus and germination of somatic embryos was MS basal medium containing $1.0 \mathrm{mgL}^{-1} 6$-BA and $0.5 \mathrm{mgL}^{-1} \mathrm{TDZ}$ with $15 \%$ potato puree, since $(5.45 \pm 0.45)$ proliferation times of embryogenic callus with the maximum average number $(18.00 \pm 0.71)$ of germinating somatic embryos was obtained on this medium (Supplementary Table S3, Figure S1A). However, although the maximum average proliferation times $(6.96 \pm 0.15)$ of embryogenic callus was obtained on MS basal medium containing $1.0 \mathrm{mgL}^{-1}$ 6-BA, $0.5 \mathrm{mgL}^{-1} \mathrm{TDZ}$ and $15 \%$ potato puree with $1.5 \mathrm{mgL}^{-1} \mathrm{ABA}$, where only $(0.80 \pm 0.37)$ germinating somatic embryos was observed (Supplementary Table S4). In addition, we also found that suitable concentrations of ABA could obviously prompt proliferation of embryogenic callus, but inhibit the germination of somatic embryos (Supplementary Table S4). Among the media tested, we also found that the proliferation times of embryogenic callus and mean numbers of germinating somatic embryos on MS basal medium containing $1.0 \mathrm{mgL}^{-1}$ 6-BA and $0.5 \mathrm{mgL}^{-1} \mathrm{TDZ}$ with $1.5 \mathrm{mgL}^{-1}$ NAA were significantly higher than that on the MS basal medium containing $1.0 \mathrm{mgL}^{-1} 6-\mathrm{BA}$ and $0.5 \mathrm{mgL}^{-1} \mathrm{TDZ}$ without NAA, respectively $(p<0.05)$ (Supplementary Table S2). The percentage of somatic embryo-derived plant ranged from $38.25 \pm 0.20 \%$ to $75.75 \pm 0.04 \%$ after 40 days of culture (Supplementary Table S5). In addition, the best medium for plant regeneration was MS basal medium, where the maximum mean percentage $(75.75 \pm 0.04 \%)$ of somatic embryo-derived plant was observed, and the next best medium was MS basal medium containing $0.5 \mathrm{mgL}^{-1}$ active carbon, where $71.25 \pm 0.04 \%$ of somatic embryo-derived plant showed no significant difference with that on MS basal medium (Supplementary Figure S1).

\subsection{Somatic Embryogenesis of Fagopyrum esculentum and Histological Analysis}

During 10 days of subculture on MS basal medium containing $1.0 \mathrm{mgL}^{-1} 6-\mathrm{BA}$ and $0.5 \mathrm{mgL}^{-1}$ TDZ with $15 \%$ potato puree, the particles germinating from rough surface of the friable embryogenic callus gradually increased in size and formed globular somatic embryos (Figure 5A). Then, the globular somatic embryos developed into the heart-shaped somatic embryos (Figure 5B). After 10-15 days of subculture, the torpedo-shaped somatic embryos were observed to formed and then developed into cotyledonary embryos (Figure 5C). After about 20 days of subculture, the mature somatic embryos were found in embryogenic callus (Figure 5D). Moreover, the different developmental stages of somatic 
embryos (globular, heart-shaped, torpedo-shaped, cotyledonary embryos) were also found in the same embryogenic callus during the subculture. In addition, histological analysis revealed that the early embryogenic callus contained yellow patches of tightly packed meristematic cells with dense cytoplasm and big nucleus (Figure 5E). The yellow meristematic cells subsequently developed into pro-embryos and later developed into globular somatic embryos (Figure 5E,F). Meanwhile, the cell wall of these meristematic cells turned thick and the nucleus moved to the edge of the cell wall; In addition, the accumulation of starch and protein achieved peaks in embryogenic callus and in globular somatic embryos (Figure 5E,F). With the development of somatic embryos, the starch grains gradually accumulated in the embryogenic cells (Figure 5G,H).
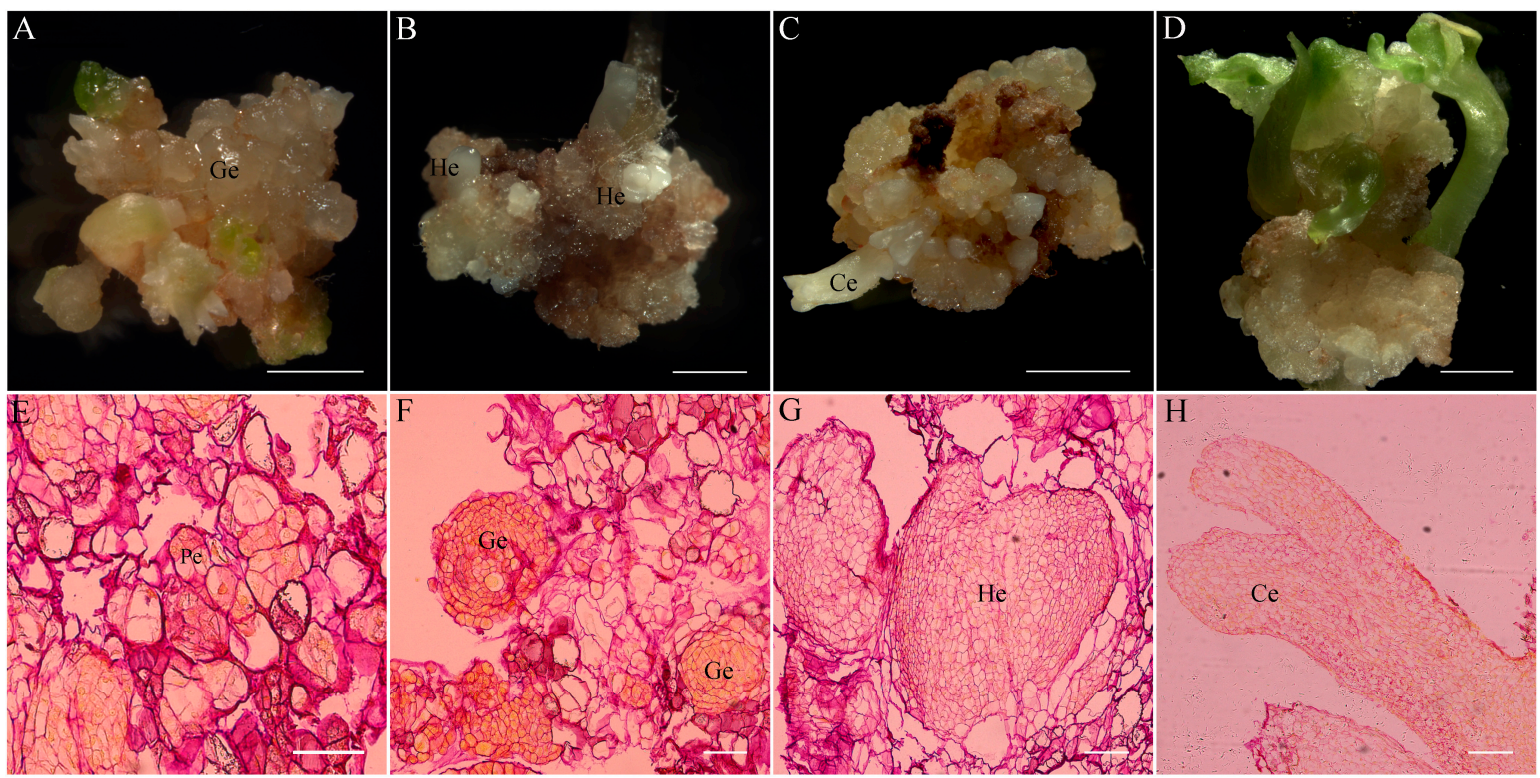

Figure 5. Somatic embryogenesis from hypocotyl explants of Fagopyrum esculentum. (A) Stage of globular somatic embryo (Ge); (B) stage of heart-shaped somatic embryos (He); (C) stage from torpedo somatic embryos to cotyledonary embryos (Ce); (D) mature somatic embryos; (E) histological section of pro-embryos (Pe); (F) histological section of globular somatic embryo; (G) histological section of heart-shaped somatic embryos; $(\mathbf{H})$ histological section of cotyledonary embryos. Scale bar: (A-D) 2 cm; (E-G) $100 \mu \mathrm{m}$; (H) $500 \mu \mathrm{m}$.

\section{Discussion}

Previous studies suggested that 2,4-D was necessary for SE in several species such as Capsicum baccatum [21], Tagetes erecta [22], Salicornia brachiate [23] and Cymbopogon winterianus [24]. High indirect somatic embryogenesis from immature embryos of buckwheat also occurred on $\mathrm{B}_{5}$ medium with $6 \%$ sucrose when $5.0 \mathrm{mgL}^{-1} 2,4-\mathrm{D}$ and $0.1 \mathrm{mgL}^{-1} \mathrm{KT}$ were supplied at the beginning of the culture period for 5 days, and then transferred to $B_{5}$ medium plus $2.2 \mathrm{mgL}^{-1} \mathrm{BAP}, 0.17 \mathrm{mgL}^{-1}$ IAA for germination of somatic embryos [14]. Another study showed that hypocotyl explants culturing in the 2,4-D-containing $\mathrm{B}_{5}$ media considerably affected the rate of proembryogenic cell complexes (PECC) development and the number of PECC produced in buckwheat [25]. In our experiment, 2,4-D in combination with cytokinins (6-BA and KT) induced compact callus from cotyledon or hypocotyl explants. When MS basal medium containing 3\% sucrose and $4.0 \mathrm{mgL}^{-1}$ 2,4-D combined with KT at appropriate concentrations, $100 \%$ of cultured hypocotyl explants were observed to produce uniform callus. However, when MS basal medium containing $3 \%$ sucrose and $2.0 \mathrm{mgL}^{-1} 2,4$-D combined with $1.5 \mathrm{mgL}^{-1} 6-\mathrm{BA}, 100 \%$ of cultured explants were observed to produce callus accompanied by a small amount of embryogenic callus. In addition, a few somatic embryos were observed to germinate directly when the initial calli were transferred to basal medium containing $2.0 \mathrm{mgL}^{-1} 6-\mathrm{BA}$ and $1.5 \mathrm{mgL}^{-1} \mathrm{TDZ}$ for subculture. All these data showed that 2,4-D was not essential for buckwheat somatic embryogenesis, although it increased 
the number of responding explants. However, TDZ in combination with 6-BA could induce yellowish white friable embryogenic callus from the green compact callus, whereas KT in combination with 6-BA could induce adventitious shoots from red-green compact callus. Moreover, TDZ and 6-BA in combination with NAA or potato puree could induce germination of buckwheat somatic embryos in our study. However, recent study suggested that a combination of $0.5 \mathrm{mgL}^{-1} 2,4-\mathrm{D}$ and $0.2 \mathrm{mgL}^{-1} \mathrm{BAP}$ with sucrose showed highest induction of SE from cotyledon and hypocotyl explants of buckwheat [16]. In addition, embryogenic callus from cotyledon of buckwheat was found to be MS medium containing $0.2 \mathrm{mgL}^{-1} \mathrm{KT}, 2.0 \mathrm{mgL}^{-1} \mathrm{BAP}$ and 3\% (w/v) sucrose [26]. All these suggested that 6-BA was necessary for buckwheat somatic embryogenesis. Other research also suggested that regeneration from nodal segments on MS medium with $1.0 \mathrm{mgL}^{-1}$ BA solidified by agar was the efficient technique of buckwheat micropropagation and in vitro maintenance [27]. Another research also indicated that treatment with BAP significantly induced shoot regeneration from cotyledon cultures of buckwheat [28]. Moreover, abnormal somatic usually occurred in this experiment. Similar results were also observed in the tissue culture described by Saraswat and Kumar [16]. TDZ in combination with NAA was proved to be the most effective for direct somatic embryo formation and regeneration in Epipremnum aureum [29]. In addition, we also found that ABA could prompt the proliferation of buckwheat embryogenic callus, but inhibit the germination of buckwheat somatic embryos.

During the somatic embryogenesis, the accumulation of starch and protein achieved peaks in embryogenic callus and in globular somatic embryos. Similar results about starch accumulation and regularity of protein formation were also observed during the SE from needles of redwood [30]. In addition, different developmental stages of somatic embryos (globular, heart-shaped, torpedo-shaped, cotyledonary embryos) were also found in the same embryogenic callus. Further challenge was to develop an efficient system for producing uniform developmental stages of somatic embryos and for the genetic manipulation of this species.

\section{Conclusions}

In this study, we developed a useful protocol for indirect somatic embryogenesis and subsequent plant regeneration from hypocotyl explants of F. esculentum. Firstly, the initial calli of hypocotyl explants were induced on MS basal medium containing $2.0 \mathrm{mgL}^{-1} 2,4-\mathrm{D}$ and $1.5 \mathrm{mgL}^{-1} 6$-BA for 30 days culture, and then the yellowish white friable embryogenic calli were developed when the initial calli were transferred to fresh MS basal medium supplemented with $1.0 \mathrm{mgL}^{-1} 6$-BA and $0.5 \mathrm{mgL}^{-1}$ TDZ two to three times subculture at 40-60 days intervals. Subsequently, the Somatic embryos were able to germinate from embryogenic callus sub-cultured on basal medium containing $1.0 \mathrm{mgL}^{-1} 6$-BA and $0.5 \mathrm{mgL}^{-1} \mathrm{TDZ}$ with $15 \%$ potato puree for 20 days subculture. Finally, the somatic embryo-derived plants were obtained when the mature somatic embryos were transferred to MS basal medium without growth regulators for 40 days culture.

Supplementary Materials: The following are available online at http://www.mdpi.com/2073-4395/9/11/768/s1, Supplementary Figure S1: Proliferation of embryogenic callus, germination of somatic embryos and plant regeneration of Fagopyrum esculentum, Table S1: Callus induction frequencies of cotyledon and hypocotyl explants on the initial cultural media, Table S2: Effects of concentrations of NAA or IAA on proliferation of embryogenic callus and germination of somatic embryos, Table S3: Effects of mashed bananas or potato puree concentrations on proliferation of embryogenic callus and germination of somatic embryos, Table S4: Effects of ABA concentrations on proliferation of embryogenic callus and germination of somatic embryos, Table S5: Plant regeneration of Fagopyrum esculentum by somatic embryogenesis on different cultural media.

Author Contributions: Y.F. wrote the manuscript. L.-X.W. carried out the experiments. Y.F., L.-X.W., Z.-W.F. and Z.-X.L. discussed the results. Z.-X.L. designed the experiments, provided project supervision and revised the manuscript. All authors have read and approved the final manuscript.

Funding: This work was supported by grants from the National Natural Science Foundation of China (Grant No. 31571736 and No. 31771867 and No. 31671755), and the Special Fund for Agro-scientific Research in the Public Interest of China (Grant No. 201303008), and the Excellent Master Dissertation Cultivation Program of Yangtze University (YS2018049).

Conflicts of Interest: The authors declare no conflict of interest. 


\section{Abbreviations}

$\begin{array}{ll}\text { 2,4-D } & \text { 2,4-Dichlorophenoxyacetic acid } \\ \text { 6-BA } & \text { 6-Benzylaminopurine } \\ \text { BAP } & \text { 6-Benzylaminopurine } \\ \text { ABA } & \text { abscisic acid } \\ \text { FAA } & \text { Formalin acetic acid alcohol } \\ \text { IAA } & \text { Indole-3-acetic acid } \\ \text { KT } & \text { Kinetin } \\ \text { MS } & \text { Murashige and Skoog } \\ \text { NAA } & \alpha \text {-Naphthalene acetic acid } \\ \text { TDZ } & N \text {-Phenyl- } N^{\prime}-1,2,3-\text { thiadiazol-5-ylurea }\end{array}$

\section{References}

1. Mizuno, N.; Yasui, Y. Gene flow signature in the S-allele region of cultivated buckwheat. BMC Plant Biol. 2019, 19, 125. [CrossRef] [PubMed]

2. Quinet, M.; Cawoy, V.; Lefèvre, I.; Van Miegroet, F.; Jacquemart, A.L.; Kinet, J.M. Inflorescence structure and control of flowering time and duration by light in buckwheat (Fagopyrum esculentum Moench). J. Exp. Bot. 2004, 55, 1509-1517. [CrossRef] [PubMed]

3. Cawoy, V.; Kinet, J.M.; Jacquemart, A.L. Morphology of nectaries and biology of nectar production in the distylous species Fagopyrum esculentum. Ann. Bot. 2008, 102, 675-684. [CrossRef] [PubMed]

4. Yabe, S.; Hara, T.; Ueno, M.; Enoki, H.; Kimura, T.; Nishimura, S.; Yasui, Y.; Ohsawa, R.; Iwata, H. Rapid genotyping with DNA micro-arrays for high-density linkage mapping and QTL mapping in common buckwheat (Fagopyrum esculentum Moench.). Breed. Sci. 2014, 64, 291-299. [CrossRef] [PubMed]

5. Oomah, B.D.; Mazza, G. Flavonoids and antioxidative activities in buckwheat. J. Agric. Food chem. 1996, 44, 1746-1750. [CrossRef]

6. Giménez-Bastida, A.; Zieliński, H. Buckwheat as a Functional Food and Its Effects on Health. J. Agric. Food Chem. 2015, 63, 7896-7913. [CrossRef] [PubMed]

7. Kreft, M. Buckwheat phenolic metabolites in health and disease. Nutr. Res. Rev. 2016, 29, 30-39. [CrossRef]

8. Li, L.Y.; Fang, Z.W.; Li, X.P.; Liu, Z.X. Isolation and Characterization of the C-class MADS-box Gene from the Distylous Pseudo-cereal Fagopyrum esculentum. J. Plant Biol. 2017, 60, 189-198. [CrossRef]

9. Cawoy, V.; Lutts, S.; Ledent, J.F.; Kinet, J.M. Resource availability regulates reproductive meristem activity, development of reproductive structures and seed set in buckwheat (Fagopyrum esculentum). Physiol. Plant. 2007, 131, 341-353. [CrossRef]

10. Kadokura, S.; Sugimoto, K.; Tarr, P.; Suzuki, T.; Matsunaga, S. Characterization of somatic embryogenesis initiated from the Arabidopsis shoot apex. Dev. Biol. 2018, 442, 13-27. [CrossRef]

11. Saeed, W.; Naseem, S.; Gohar, D.; Ali, Z. Efficient and reproducible somatic embryogenesis and micropropagation in tomato via novel structures-Rhizoid Tubers. PLoS ONE 2019, 14, e0215929. [CrossRef] [PubMed]

12. Ming, N.G.J.; Binte Mostafiz, S.; Johon, N.S.; Abdullah Zulkifli, N.S.; Wagiran, A. Combination of Plant Growth Regulators, Maltose, and Partial Desiccation Treatment Enhance Somatic Embryogenesis in Selected Malaysian Rice Cultivar. Plants (Basel) 2019, 8, 144. [CrossRef] [PubMed]

13. Lowe, K.; La Rota, M.; Hoerster, G.; Hastings, C.; Wang, N.; Chamberlin, M.; Wu, E.; Jones, T.; Gordon-Kamm, W. Rapid genotype “independent" Zea mays L. (maize) transformation via direct somatic embryogenesis. In Vitro Cell Dev. Biol. Plant 2018, 54, 240-252. [CrossRef] [PubMed]

14. Nešković, M.; Vujičić, R.; Budimir, S. Somatic embryogenesis and bud formation from immature embryos of buckwheat (Fagopyrum esculentum Moench). Plant Cell Rep. 1987, 6, 423-426. [CrossRef]

15. Kwon, S.J.; Han, M.H.; Huh, Y.S.; Roy, S.K.; Lee, C.W.; Woo, S.H. Plantlet regeneration via somatic embryogenesis from hypocotyls of common buckwheat (Fagopyrum esculentum Moench). Korean J. Crop Sci. 2013, 58, 331-335. [CrossRef]

16. Saraswat, R.; Kumar, M. Plant regeneration in buckwheat (Fagopyrum esculentum Moench) via somatic embryogenesis and induction of meristemoids in abnormal embryos. Plant Tissue Cult. E Biotech. 2019, 29, 33-47. [CrossRef] 
17. Murashige, T.; Skoog, F. A revised medium for rapid growth and bioassays with tobacco tissue cultures. Physiol. Plant. 1962, 15, 473-497. [CrossRef]

18. Zeng, S.J.; Cheng, S.J.; Zhang, J.L.; Zhao, F.P. Embryo Culture and Propagation of Dendrobium in Vitro. Acta Hortic. Sin. 1998, 25, 75-80.

19. Jiang, J.L. Study on the Effects of Several Additives on the PLB Proliferation and Tube Seedlings Growth of Oncidium 'Gower Ramsey'. Subtrop. Plant Sci. 2012, 41, 8-14. [CrossRef]

20. Liu, Z.X.; Xiong, H.Y.; Li, L.Y.; Fei, Y.J. Functional Conservation of an AGAMOUS Orthologous Gene Controlling Reproductive Organ Development in the Gymnosperm species Taxus chinensis var. Mairei. J. Plant Biol. 2018, 61, 50-59. [CrossRef]

21. Venkataiah, P.; Bhanuprakash, P.; Suman Kalyan, S.; Subhash, K. Somatic embryogenesis and plant regeneration of Capsicum baccatum L. J. Genet. Eng. Biotechnol. 2016, 14, 55-60. [CrossRef] [PubMed]

22. Espinoza, P.E.V.; Benítez-García, I.; Peralta, A.L.L.; Paredes-López, O.; Del Villar-Martínez, A.A. Somatic embryogenesis from leaf explants of Tagetes erecta L. Plant Biotechnol. (Tokyo) 2017, 34, 187-192. [CrossRef] [PubMed]

23. Rathore, M.S.; Paliwal, N.; Anand, K.G.V.; Agarwal, P.K. Somatic embryogenesis and in vitro plantlet regeneration in Salicornia brachiata Roxb. Plant Cell Tissue Organ Cult. 2015, 120, 355-360. [CrossRef]

24. Dey, T.; Bhattacharya, S.; Ghosh, P.D. Somatic embryogenesis from rhizome explants of Cymbopogon winterianus. Biol. Plant. 2010, 54, 325-328. [CrossRef]

25. Gumerova, E.A.; Galeeva, E.I.; Chuyenkova, S.A.; Rumyantseva, N.I. Somatic Embryogenesis and Bud Formation on Cultured Fagopyrum esculentum Hypocotyls. Rus. J. Plant Physiol. 2003, 50, 640-645. [CrossRef]

26. Woo, S.H.; Nair, A.; Adachi, T.; Campbell, C.G. Plant regeneration from cotyledon tissues of common buckwheat (Fagopyrum esculentum Moench). In Vitro Cell. Dev. Biol.-Plant. 2000, 36, 358-361. [CrossRef]

27. Klčová, L.; Gubišová, M. Evaluation of Different Approaches to Buckwheat (Fagopyrum esculentum Moench) Micropropagation. Czech J. Genet. Plant Breed. 2008, 44, 66-72. [CrossRef]

28. Lee, S.Y.; Kim, Y.K.; Uddin, M.R.; Park, N. An efficient protocol for shoot organogenesis and plant regeneration of buckwheat (Fagopyrum esculentum Moench). Rom. Biotechnol. Lett. 2009, 14, 4524-4529.

29. Zhang, Q.; Chen, J.; Henny, R.J. Direct somatic embryogenesis and plant regeneration from leaf, petiole, and stem explants of Golden Pothos. Plant Cell Rep. 2005, 23, 587-595. [CrossRef]

30. Liu, C.; Xia, X.; Yin, W.; Huang, L.; Zhou, J. Shoot regeneration and somatic embryogenesis from needles of redwood (Sequoia sempervirens (D.Don.) Endl.). Plant Cell Rep. 2006, 25, 621-628. [CrossRef] 